\title{
Combination Of The Methods Of Symmetrical Components And Double Entry To Increase The Reliability Of Digital Differential Relay Protection
}

\author{
Aleksandr L. Kulikov ${ }^{1, *}$, Boris V. Papkov², Anton A. Kolesnikov ${ }^{3}$, and Vladimir Ju. Vukolov ${ }^{1}$ \\ ${ }^{1}$ Nizhny Novgorod State Technical University n.a. R.E. Alekseev, 603950, Nizhny Novgorod, Russian Federation \\ ${ }^{2}$ Nizhny Novgorod State University of Engineering and Economics, 606340, Knyaginino, Russian Federation \\ ${ }^{3}$ LLC Scientific-Production Enterprise Microprocessor technology, Nizhny Novgorod, Russian Federation
}

\begin{abstract}
The method of symmetrical components is one of the main methods used to calculate asymmetric modes in electric power systems. To increase the reliability of digital differential relay protection in case of asymmetric faults, a combination of symmetric components and double entry methods is proposed. It is supposed to compile balance equations, to apply the theory of graphs and matrices, and the estimation of reliability indicators is carried out on the basis of the method of Markov chains. The obtained results allow to make a conclusion about the prospects of implementing a differential protection using the method of double entry and symmetrical components in the electrical networks.
\end{abstract}

\section{Introduction}

The method of symmetrical components is a main transformation that is applied in relay protection (RP) to determine ground faults and detect asymmetry [1]. One of its features is the universality and the ability to implement in decentralized and centralized protection, for example, in the centralized protection against ground faults [2].

As a development of the centralized modification of using the method of symmetric components, it is proposed to develop a differential current protection with the implementation of the methods of symmetric components and double entry to increase the reliability of electrical networks [3].

\section{Realization of proposed protection}

To illustrate the operation of protection, consider the fragment of the electrical distribution network shown in fig. $1 \mathrm{a}$.

The structure of the scheme displayed as a unidirectional graph (fig. 1b) with arcs representing the high-voltage units and the vertices representing the protected items - busbar, transformer and transmission line. Then, each vertex of the graph is represented by the special matrix of currents whose rows represent the vertices of the graph, the columns - the separation of arcs connecting the vertex on the directed to it and directed away from it.

For determining the location of fault, protection compares the currents on differential principle for particular regions and detects potentially damaged item.
For all graph vertices with degree $>1$ compile equations in matrix form for the sum of the currents different sequences (positive, negative, zero) at the nodes. Mathematical calculations for the proposed approach are detailed in [3, 4].

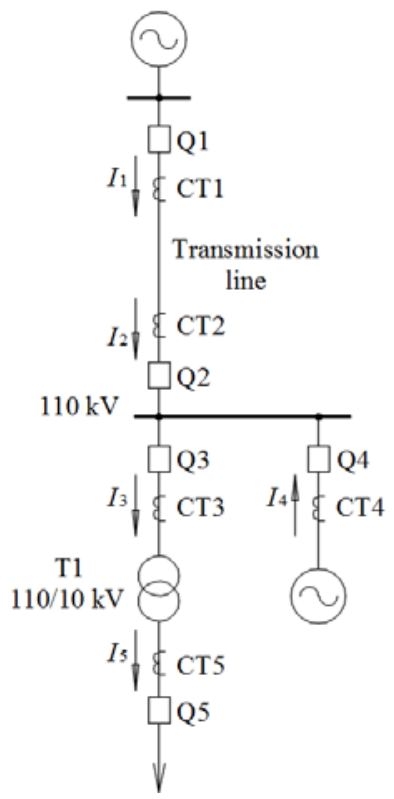

a)

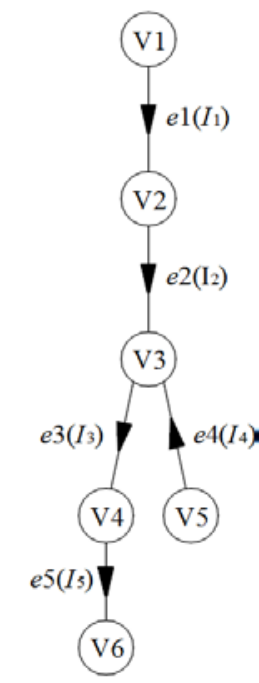

b)
Fig. 1. Scheme of fragment of distribution network and unidirectional graph.

Then it is determined whether to trigger starting on fault in the region, or there is a current transformers (CT) or communication lines (CL) fault. The presence of a fault is determined using the method of double entry.

\footnotetext{
${ }^{*}$ Corresponding author: inventor61@mail.ru
} 
Since each arc of the graph is reflected with the same weight (current value) in the matrices twice: as an arc, associated with the vertex directed to one matrix, and as the arc associated with the vertex directed from another matrix, in the case getting wrong values is the sum of incoming and outgoing currents in the two matrices becomes incorrect, but the total differential current of the whole network remains equal to zero. In case of observance of rule of detection of the fault and maintaining a sum of currents for the entire network is equal to zero, a CT or CL fault is detected.

Protection also detect the presence of ground fault in networks with isolated neutral, the presence of asymmetry, the type of asymmetric fault (Single Line-toGround, Line-to-Line, Double Line-to-Ground) and damaged phase.

A sign of the functioning of the differential protection for different ratios of currents and the results of performing matrix operations for this scheme is shown in Table 1 on the example of protection for $110 \mathrm{kV}$ transmission line (graph vertex V2). The SMV2 variables derived from matrix operations determine the conditions for the presence of faults protection in the protection zone. The SUM variables determine the total differential current of the network. Table 1 also contains the variable Id - setpoint of the differential protection.

Table 1. Results matrix operations and signs of the functioning of the protection.

\begin{tabular}{|c|c|c|c|c|c|c|c|c|}
\hline \multicolumn{8}{|c|}{ The resulting value matrix operations } & \multirow{3}{*}{$\begin{array}{c}\text { Signs } \\
\text { of } \\
\text { fault }\end{array}$} \\
\hline \multicolumn{4}{|c|}{ SMV2 } & \multicolumn{4}{|c|}{ SUM } & \\
\hline$A$ & $B$ & $C$ & 0 & $A$ & $B$ & $C$ & 0 & \\
\hline 0 & 0 & 0 & 0 & 0 & 0 & 0 & 0 & $\begin{array}{l}\text { No } \\
\text { faults }\end{array}$ \\
\hline$>I d$ & $>I d$ & $>I d$ & 0 & $>I d$ & $>I d$ & $>I d$ & 0 & 3 phase \\
\hline$>$ Id & $>I d$ & 0 & 0 & $>$ Id & $>I d$ & 0 & 0 & $\mathrm{AB}$ \\
\hline 0 & $>$ Id & $>I d$ & 0 & 0 & $>I d$ & $>I d$ & 0 & $\mathrm{BC}$ \\
\hline$>I d$ & 0 & $>I d$ & 0 & $>I d$ & 0 & $>I d$ & 0 & $\mathrm{CA}$ \\
\hline$>I d$ & 0 & 0 & $>I d$ & $>I d$ & 0 & 0 & $>I d$ & $\begin{array}{l}\text { A to } \\
\text { Ground }\end{array}$ \\
\hline 0 & $>$ Id & 0 & $>$ Id & 0 & $>$ Id & 0 & $>$ Id & $\begin{array}{l}\text { B to } \\
\text { Ground }\end{array}$ \\
\hline 0 & 0 & $>$ Id & $>I d$ & 0 & 0 & $>I d$ & $>I d$ & $\begin{array}{l}\text { C to } \\
\text { Ground }\end{array}$ \\
\hline$>I d$ & $>$ Id & 0 & $>I d$ & $>$ Id & $>$ Id & 0 & $>$ Id & $\begin{array}{l}\mathrm{AB} \text { to } \\
\text { Ground }\end{array}$ \\
\hline 0 & $>$ Id & $>I d$ & $>I d$ & 0 & $>I d$ & $>$ Id & $>I d$ & $\begin{array}{l}\text { BC to } \\
\text { Ground }\end{array}$ \\
\hline$>I d$ & 0 & $>I d$ & $>I d$ & 0 & 0 & 0 & $>I d$ & $\begin{array}{l}\text { CA to } \\
\text { Ground }\end{array}$ \\
\hline$>$ Id & 0 & 0 & $>I d$ & 0 & 0 & 0 & 0 & CT2 A \\
\hline 0 & $>I d$ & 0 & $>I d$ & 0 & 0 & 0 & 0 & CT2 B \\
\hline 0 & 0 & $>I d$ & $>I d$ & 0 & 0 & 0 & 0 & CT2 C \\
\hline
\end{tabular}

\section{Quantitative assessment of the reliability of the proposed protection}

To quantify the advantages of the proposed technical solutions from the point of view of reliability, using the method of Markov chains. This method is often used to describe the processes of failure and repair with the elementary streams, and is most suitable for calculating reliability of system of relay protection (SRP) [5-7]. In this paper applies the mathematical model of the functioning of the SRP, presented in [6]. The distribution laws of failure and repair will accept exponential.

Taking into account specificity of the analyzed differential protection, define two types of protection failures:

- undesired-tripping protection failures (in the absence of fault on the protected object);

- fail-to-operate protection failures (in case of fault on the protected object).

This approach is used in several papers, e.g. [9].

In fig. 2 presents fragment of distribution network with two variants of the relay protection system organization is presented. In first case (fig. 2a) the system of RS consisting of differential line protection (DLP), differential bus protection (DBP) and transformer differential protection (DTP) is shown; in the second case (fig. 2b) - a system consisting of distributed DLP, DBP, DTP and differential network protection (DNP), issuing a signal that blocks the protection of a fault CT or CL.

Calculate reliability indices for both cases on the basis $[6,10]$, and information from the manufacturers of relay protection.

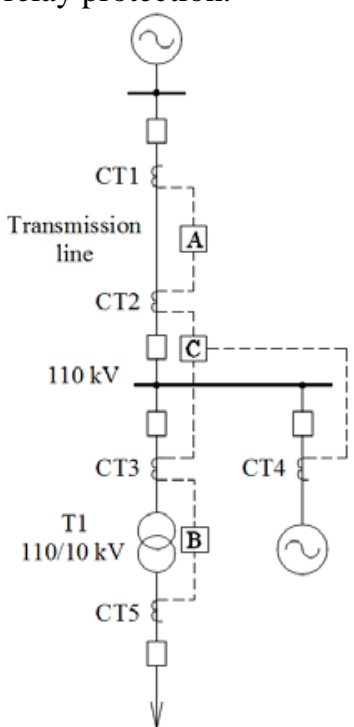

a)

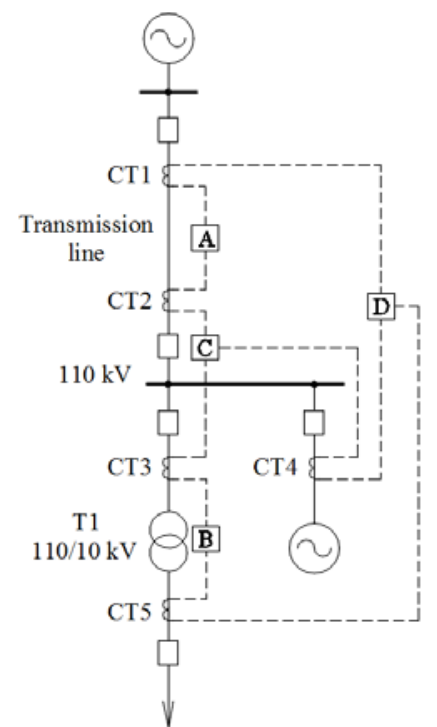

b)
Fig. 2. Scheme of connection protections to $\mathrm{CT}$ a) distributed protection system (A - DLP, B - DTP, C - DBP), b) the system includes DNP (A - DLP, B - DTP, C - DBP, D DNP).

\subsection{Mode 1: absence of fault on the protected object}

In fig. 3 shows graphs of states and transitions in an absence of fault on the protected object mode. Here: Ew-state SRP without failures; $\mathrm{A}_{1}, \mathrm{~B}_{1}, \mathrm{C}_{1}, \mathrm{D}_{1}$, $\mathrm{CT} 1_{1} \ldots \mathrm{CT} 5_{1}$ - the state of the SRP in the presence of defects that could lead to undesired-tripping protection failures of devices of relay protection A, B, C or D, and, as a result, failure of the SRP in general; $\mu_{1}, \mu_{2}$-repair rates of the relay protection and CT. 


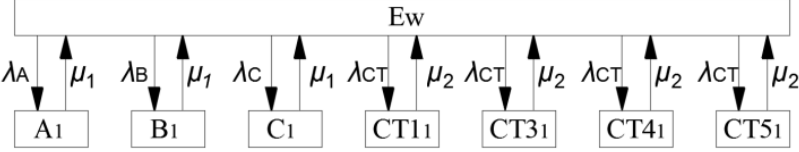

$$
\begin{aligned}
& \text { a) }
\end{aligned}
$$

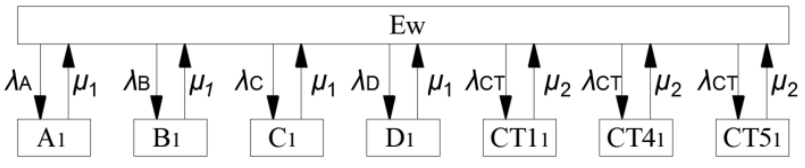

$$
\begin{aligned}
& \text { b) }
\end{aligned}
$$

Fig. 3. Graphs of states and transitions for an absence of fault on the protected object mode a) system without DNP, b) system with DNP.

Convert the graphs (fig. 3) to the form shown in fig. 4 , where $E_{1}$ - failure state of SRP, $\lambda_{1}$ - the resulting failure rate of protection.

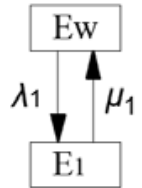

Fig. 4. Converted graph of states and transitions for an absence of fault on the protected.

Define the probability $P_{1}(t)$ that the system is in state $\mathrm{E}_{1}$, which is an emergency, for random time $t$. Form a system of differential equations describing a graph, where $P_{w}(t)$ - the probability of location the system in state without failures $E_{\mathrm{w}}$.

$$
\left.\begin{array}{l}
\frac{d P_{w}(t)}{d t}=-\lambda_{1} \cdot P_{w}(t)+P_{1}(t) \cdot \mu_{1} \\
\frac{d P_{1}(t)}{d t}=\lambda_{1} \cdot P_{w}(t)-P_{1}(t) \cdot \mu_{1}
\end{array}\right\}
$$

Normalizing expression, the meaning of which is that the researched system located in state $E_{1}$ or $E_{w}$ as constituting a complete group of events, has the form

$$
P_{w}(t)+P_{1}(t)=1
$$

As at the initial moment of operation of the system at $t=0$ the system is in state without failures:

$$
P_{w}(0)=1, P_{1}(0)=0
$$

As a result of solve the system of differential equations a function of the unreadiness probability

$$
q(t)=P_{1}(t)=\frac{\lambda_{1}}{\lambda_{1}+\mu_{1}} \cdot\left(1-\exp \left[-\left(\lambda_{1}+\mu_{1}\right) t\right]\right)
$$

Make an assessment of the probability of failure-free operation of the SRP. The graph for the calculation will look similar as the graph in fig. 6 with the difference that it will not be possible to transition from state $E_{1}$ to $\mathrm{Ew}$, that is excludes repair rate $\mu_{1}$. This circumstance is due to the fact that when system fails (transition to absorbing state $E_{1}$ ), the experiment is finished - the system cannot leave this state.

Due to absence of repair instead of a system of differential equations (1), the result will be an expression of the probability of failure-free operation (PFFO), with exponential distribution law:

$$
R(t)=P_{w}(t)=\exp \left[-\left(\lambda_{1} \cdot t\right)\right]
$$

In fig. 5 shown the dependences of the function of the unreadiness probability of SRP, and functions of the PFFO on the average time between checks.

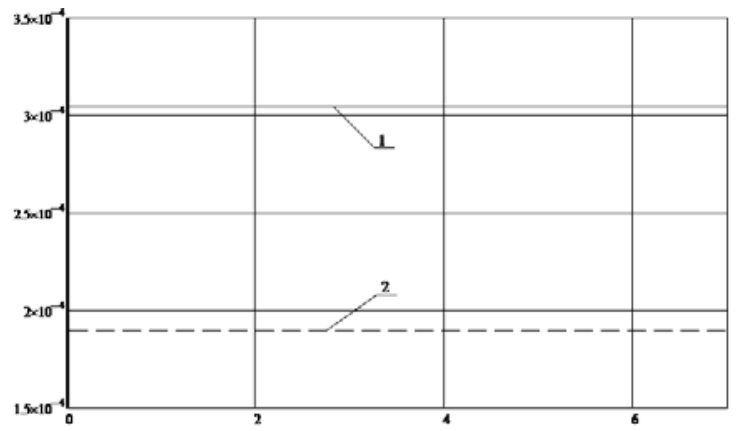

a)

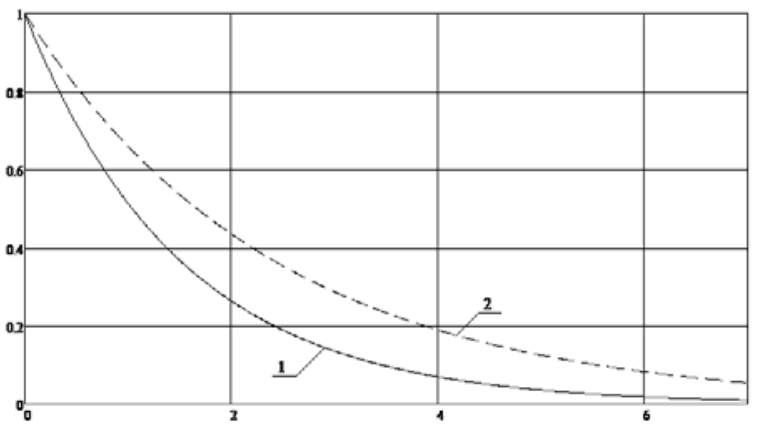

b)

Fig. 5. Function of the unreadiness of SRP (a) and function PFFO of SRP (b). 1 - system without DNP; 2 system with DNP.

The analysis of graphs in fig. 5a shows that the functions of unreadiness probability are straight lines, the values of which are close to zero. This is due to the fact that for the considered case, the repair process can be considered instantaneous.

\subsection{Mode 2: in case of fault on the protected object}

In fig. 6 shows graphs of states and transitions in case of fault on the protected object mode. Here: $E_{w}-$ state SRP without failures; $A_{1}, B_{1}, C_{1}, D_{1}$ - the states of the SRP in the presence of defects that could lead to fail-to-operate protection failures of devices of relay protection; $\mathrm{A}_{1} \mathrm{D}_{1}$, $B_{1} D_{1}, C_{1} D_{1}$ - states with defects, that happens at the same time in two terminals; $\mu_{1}, \mu_{2}$ - repair rates.

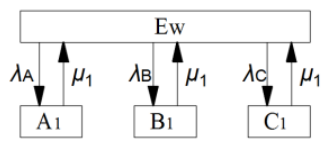

a) 

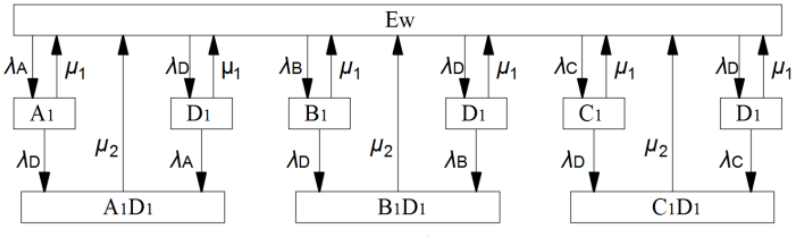

b)

Fig. 6. Graphs of states and transitions in case of fault on the protected object mode a) system without DNP, b) system with DNP.

Convert the graphs (fig. 6) to the form shown in fig. 7. Since the damage and CT cables cannot lead to fail-to-operate protection failures, they are not included in the scheme.

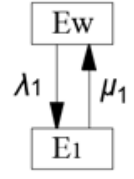

a)

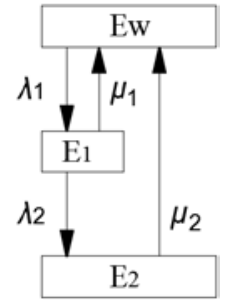

b)
Fig. 7. Converted graphs of states and transitions in case of fault on the protected object mode

a) system without DNP, b) system with DNP.

The system of differential equations for the system includes a DLP, DBP and DTP and SRP with DNP describing the graph (fig.7a), are similar as (1) and, accordingly, the expressions for functions of unreadiness probability and probability of failure-free operation will be similar.

The calculation for the system with DNP.

Determine the probability that the system is situated in the state $E_{2}$. The system of differential equations describing the graph:

$$
\left.\begin{array}{l}
\frac{d P_{w}(t)}{d t}=-\lambda_{1} \cdot P_{w}(t)+\mu_{1} \cdot P_{1}(t)+\mu_{2} \cdot P_{2}(t) \\
\frac{d P_{1}(t)}{d t}=\lambda_{1} \cdot P_{w}(t)-\left(\lambda_{2}+\mu_{1}\right) \cdot P_{1}(t) \\
\frac{d P_{2}(t)}{d t}=\lambda_{2} \cdot P_{1}(t)-\mu_{2} \cdot P_{2}(t)
\end{array}\right\}
$$

Solving the system of equations (3), the unreadiness probability

$$
q(t)=P_{2}(t)=0,14 \cdot e^{-0,502 \cdot t}-0,15 \cdot e^{-0,467 \cdot t}+0,0104
$$

Graph for the calculation of assessment of the probability of failure-free operation will look similar as the graph shown in fig. $7 \mathrm{~b}$, with the difference that it will not be possible transition from state $\mathrm{E}_{2}$ в Ew.

The system of differential equations describing the graph:

$$
\left.\begin{array}{l}
\frac{d P_{w}(t)}{d t}=-\lambda_{1} \cdot P_{w}(t)+\mu_{1} \cdot P_{1}(t) \\
\frac{d P_{1}(t)}{d t}=\lambda_{1} \cdot P_{w}(t)-\left(\lambda_{2}+\mu_{1}\right) \cdot P_{1}(t) \\
\frac{d P_{2}(t)}{d t}=\lambda_{2} \cdot P_{1}(t)
\end{array}\right\}
$$

Solving the system of equations (4), the probability of failure-free operation

$$
R(t)=1-P_{2}(t)=-0,0087 \cdot e^{-0,532 \cdot t}+1,008 \cdot e^{-0,0046 t}+0,001
$$

In fig. 8 shown the dependences of the function of the unreadiness probability of SRP, and functions of the probability of failure-free operation on the average time between checks.

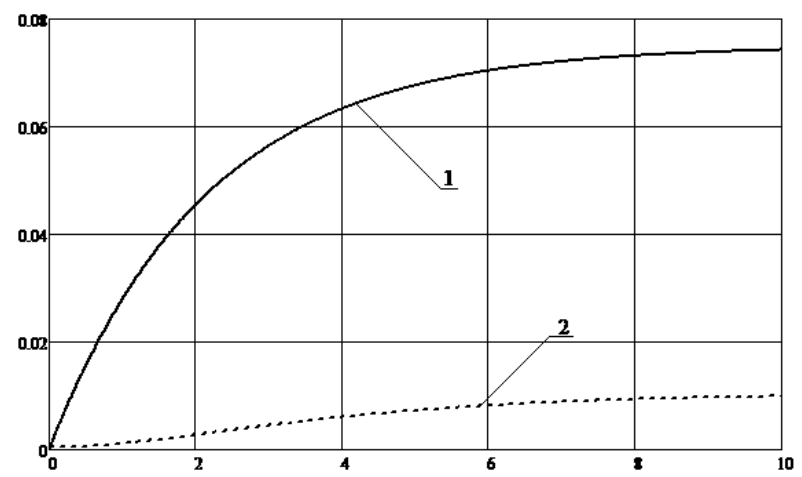

a)

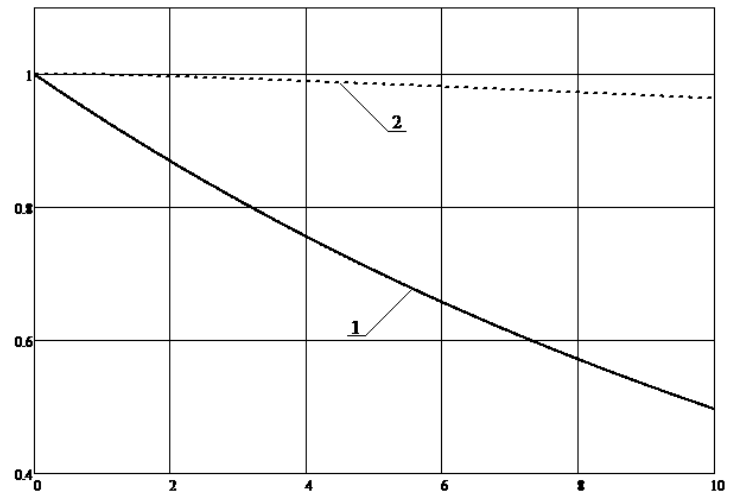

b)

Fig. 8. Function of the unreadiness of SRP (a) and function PFFO of SRP (b).

1 - system without DNP, 2 - system with DNP.

From the results of the calculation it follows that there is an increase reliability of the relay protection using the proposed method of organization of protection, absence of fault on the protected object: up to 1.5 times in the function of unreadiness and up to 4.5 times in the probability of failure-free operation; in case fault on the protected object mode up to 10.4 times in the function of unreadiness and up to 1.5 times in the probability of failure-free operation.

\section{Conclusions}

It is perspective to combine combination of the methods of symmetrical components and double entry in digital differential protection in electrical networks of different voltage classes. 
Due to the method of symmetrical components, the proposed protection selectively detects faults, by defining the damaged phases, and due to the double entry method exclude CT or communication lines fault. Protection has high flexibility when changing the configuration of the electrical network.

The proposed technical solution can increase the reliability of the differential relay protection, what follows from by the results of practical calculations.

\section{References}

1. G.Je. Lint. Simmetrichnye sostavljajushhie v relejnoj zashhite (Moscow, Jenergoatomizdat, 1996)

2. V. Gorjunov, Novosti jelektrotehniki 2017. 2(104)3(105), (2017)

3. A.L. Kulikov, V.Ju. Vukolov, A.A. Kolesnikov, Vestnik NGIEI. 2 (69), 71 (2017)

4. A.L. Kulikov, V.Ju. Vukolov, A.A. Kolesnikov, M.D Obalin, Jelektricheskie stancii. 1 (1038), 40-51 (2018)

5. B.H. Smeets, M.H.J. Bollen, Stochastic modelling of protection systems: comparison of four mathematical techniques (Eindhoven, TU/e, 1995)

6. A.I. Shalin, Nadezhnost' i diagnostika relejnoj zashhity jenergosistem (Novosibirsk, NGTU, 2002)

7. B.V. Papkov, A.L. Kulikov, Teorija sistemy $i$ sistemnyj analiz dlja jelektrojenergetikov (Jurajt, 2016)

8. Je.P. Smirnov, Elektrichestvo, 9, 44 (1965)

9. A. Khurram, H. Ali, A. Tariq, O. Hasan, Proc. of int. workshop Formal Methods for Industrial Critical Systems, 169-183 (2013)

10. Ju.B. Guk, Teorija nadezhnosti $v$ jelektrojenergetike, (Leningrad, Energoatomizdat, 1990) 